\title{
Airway response of children with primary ciliary dyskinesia to exercise and $\beta_{2}$-agonist challenge
}

\author{
G.E. Phillips*, S. Thomas+, S. Heather+, A. Bush**
}

Airway response of children with primary ciliary dyskinesia to exercise and $\beta_{2}$-agonist challenge. G.E. Phillips, S. Thomas, S. Heather, A. Bush. CERS Journals Ltd 1998.

ABSTRACT: In primary ciliary dyskinesia (PCD), chest physiotherapy for airway clearance is essential. Exercise and inhaled $\beta_{2}$-agonists can produce bronchodilation thereby augmenting physiotherapy. However, both can also cause bronchoconstriction, and the effects of these stimuli in PCD are not known.

In a preliminary study, the mean coefficients of variation for forced expiratory volume in one second (FEV1), forced vital capacity (FVC) and peak expiratory flow rate (PEFR) in children with PCD were determined. They were 5.4\%, $4.4 \%$ and $8.4 \%$, respectively. Twelve children with PCD and 12 normal children performed pulmonary functions under resting conditions; during and after a validated treadmill exercise test; and before and 15 min after $200 \mu \mathrm{g}$ of inhaled salbutamol.

At baseline, FEV1, FVC, forced mid-expiratory flow (FEF25-75\%) and PEFR were significantly reduced in the PCD group compared with the control group. Exercise produced a significant increase in PEFR in the PCD group. There was no significant difference between the groups in response to salbutamol. Within the PCD group, exercise produced a significantly greater increase in PEFR than $\beta_{2}$-agonist therapy.

In conclusion, in children with primary ciliary dyskinesia there is evidence of obstructive pulmonary disease. In these children, exercise is a more potent stimulus for bronchodilation than by inhaled $\beta_{2}$-agonists. Enhancement of airway clearance may best be achieved by encouraging patients to exercise before physiotherapy rather than by inhaling $\beta_{2}$-agonists, but the effects of each should be assessed for each individual before instigating treatment.

Eur Respir J 1998; 11: 1389-1391.
*Dept of Physiotherapy, **Dept of Paediatric Respiratory Medicine, +Pulmonary Function Unit, Royal Brompton Hospital, London, UK.

Correspondence: G. Phillips

Dept of Physiotherapy

King's College London

Campden Hill Road

London W8 7AH

UK

Fax: 441713334032

Keywords: Bronchodilation

exercise

physiotherapy

primary ciliary dyskinesia

Received: July 301997

Accepted after revision February 81998
Primary ciliary dyskinesia (PCD), formerly referred to as immotile cilia syndrome, is an autosomal recessive disorder, characterized by chronic upper and lower respiratory tract infection, and in 50\% cases, mirror image organ arrangement or situs inversus [1]. Untreated, chronic lower respiratory tract infection leads to bronchiectasis, and previous studies have described abnormalities of pulmonary function compatible with airways obstruction [2-4]. Airflow limitation in children with PCD has not specifically been examined nor intrasubject variability formally assessed. It is known that suppurative lung disease can increase the coefficient of variation of spirometry, for example in cystic fibrosis, the variability of forced expiratory volume in one second (FEV1) may be up to $15 \%$ within an individual [5]. Where respiratory disease is characterized by an obstructive airways pattern, a spontaneous variability in the degree of obstruction may be demonstrated [6]. Inflammatory lung disease affects the response to exercise; asthmatics characteristically bronchoconstrict [7], whereas patients with cystic fibrosis may bronchodilate $[8,9]$. Conversely, patients with cystic fibrosis may bronchoconstrict when $\beta_{2}$-agonists are inhaled [10]. The eff-ects of these stimuli in PCD have not been characterized. These changes are of more than theoretical importance. The mainstay of treatment for PCD involves chest physiotherapy to enhance clearance of bronchial secretions.
It would clearly be advantageous to ensure maximal bronchodilation prior to physiotherapy.

The purpose of this study was thus to ascertain if children with PCD had evidence of reversible airway obstruction and if so, how bronchodilation could best be achieved to augment airway clearance with physiotherapy.

\section{Methods}

\section{Subjects}

We studied 12 children with PCD (males $n=7$; median age $11 \mathrm{yrs}$; range $7-15 \mathrm{yrs}$ ) and 12 normal children acted as controls (males $n=6$; median age 11 yrs; range 8-14 yrs). The diagnosis of PCD [11] was based on a compatible clinical picture, reduced or absent ciliary beat frequency and abnormal appearances on electron microscopy of cilia in the absence of local infection (outer dynein arm defect $n=3$; inner dynein arm defect $n=2$; outer and inner arm detects $n=2$; dynein arms absent $n=4$; inner arm and radial spoke defect $n=1$ ). Normal children recruited for the study were siblings, friends or family friends of the children with PCD with no history of chronic or recent acute respiratory problems, used no medication, and had a normal physical examination and spirometry. Siblings of patients with PCD are automatically screened for the disease 
as clinical routine. The study was approved by the Royal med consent was given by all subjects and their parents.

\section{Procedures}

Intrasubject variability of spirometry in children with PCD was determined. Ten children (eight of whom went forward to complete the airway responses study) performed ten successive flow volume loops using a Compact Vitalograph spirometer (Vitalograph, Buckingham UK). The mean coefficients of variation were: $\mathrm{FEV} 1=5.4 \%$, forced vital capacity $(\mathrm{FVC})=4.4 \%$ and peak expiratory flow rate $(\mathrm{PEFR})=8.4 \%$. Thus, for the purpose of this study, we considered the criteria for a significant change in these measurements to be $11 \%, 9 \%$ and $17 \%$, respectively.

The children recruited for the study attended the Pulmonary Function Unit at the Royal Brompton Hospital as outpatients. They had abstained from $\beta_{2}$-agonists for at least $4 \mathrm{~h}$ prior to participating and from vigorous exercise or a heavy meal for $2 \mathrm{~h}$. The study procedures were explained, and the children familiarized with all the equipment. Baseline pulmonary function was recorded as the best of three flow volume loops, using the Compact Vitalograph. Before each study period, the spirometer underwent a volume calibration using a $1 \mathrm{~L}$ syringe. Next, a treadmill exercise test was performed in an air-conditioned laboratory according to standardized protocol [12]. The treadmill was inclined at $15 \%$, and the speed adjusted to produce a heart rate of $65-85 \%$ of the subjects predicted maximum (210 - (0.65 or $0.85 \times$ age in years $))$ [13]. Heart rate was monitored continuously by surface electrocardiography, and arterial oxygen saturation by pulse oximetry (Ohmeda Biox 3700, Ohmeda, Boulder, CO, USA). Peak flow measurements were made with a Wright Peak Flow meter (Ferraris, London, UK) immediately prior to exercise, and every two minutes during the exercise period. Subjects exercised for $8 \mathrm{~min}$. On completion of exercise, further peak flow measurements were made every minute for $5 \mathrm{~min}$, every $5 \mathrm{~min}$ for the next $20 \mathrm{~min}$, with the final measurements being made at $1 \mathrm{~h}$. The exercise tests were supervised by a single observer, blind to the peak flow measurements. Finally, when the children had returned spontaneously to their baseline lung function, bronchodilator response was assessed by giving $200 \mu \mathrm{g}$ salbutamol via a metered-dose inhaler and spacer device under supervision. PEFR and the best of three flow volume loops were recorded before and 15 min after administration of the bronchodilator.

\section{Analysis}

The percentage rise in PEFR and percentage fall in PEFR with exercise were calculated for each subject in Brompton Hospital Ethics committee, and written infor-

accordance with standard practice [12]. The Mann-Whitney test was used to compare pulmonary function between the two groups (alternative hypothesis two-sided). To compare the rise in PEFR with exercise to that occurring in response to $\beta_{2}$-agonist therapy, a paired t-test was used (two-sided alternative hypothesis). For all analyses the result was considered statistically significant if $\mathrm{p}<0.05$.

To determine a clinically significant bronchodilator response, the percentage change in FEV1 was calculated. In accordance with the coefficient of variation study, a significant response was recorded if the change was $>11 \%$.

For baseline assessment of pulmonary function, predicted values from Cotes [14] and Polgar and Promadhat [15] were used.

\section{Results}

The control children had normal lung function with the exception of three where forced mid-expiratory flow (FEF $25-75 \%$ ) was only $60 \%$ of the predicted value [15]. Baseline pulmonary function for the PCD subjects is given in table 1 . The children with PCD had significantly reduced mean FEV1 $(\mathrm{p}<0.002)$, FVC $(\mathrm{p}<0.03)$, FEF25-75\% ( $\mathrm{p}<0.01)$ and PEFR $(\mathrm{p}<0.002)$ compared with the control children. Table 2 shows the changes in PEFR in response to exercise for the children with PCD. Five of twelve children with PCD had a significant rise in PEFR $(>17 \%)$ on exercise. A further five had equivocal rises $(>10 \%)$. Of the PCD subjects who demonstrated a rise in PEFR, PEFR remained elevated $30 \mathrm{~min}$ after cessation of exercise. An hour after exercise, 6 subjects still had a PEFR greater

Table 2. - Pulmonary ciliary dyskinesia (PCD) subjects changes in peak expiratory flow rate (PEFR) and forced expiratory volume in one second $\left(\mathrm{FEV}_{1}\right)$ in response to exercise and to $\beta_{2}$-agonist salbutamol

\begin{tabular}{lccc}
\hline $\begin{array}{l}\text { PCD } \\
\text { subject }\end{array}$ & $\begin{array}{c}\text { \% Rise in } \\
\text { PEFR with } \\
\text { exercise }\end{array}$ & $\begin{array}{c}\text { \% Fall in } \\
\text { PEFR with } \\
\text { exercise }\end{array}$ & $\begin{array}{c}\text { \% Change in } \\
\text { FEV1 with } \\
\beta \text {-agonist }\end{array}$ \\
\hline 1 & 10 & 6 & -5.6 \\
2 & $17^{*}$ & 2 & -10.7 \\
3 & $23^{*}$ & 0 & 0 \\
4 & $20^{*}$ & 0 & -1.1 \\
5 & $23^{*}$ & 0 & 5.6 \\
6 & -2 & $26^{*}$ & $12.9^{*}$ \\
7 & 7 & $15^{*}$ & 8.2 \\
8 & 16 & 2 & $12.6^{*}$ \\
9 & $34^{*}$ & $31^{*}$ & $24^{*}$ \\
10 & 13 & 3 & 1.8 \\
11 & 12 & 2 & 4.3 \\
12 & 11 & 5 & 2.1 \\
\hline *: significant clinical responses (see text for explanation).
\end{tabular}

Table 1. - Baseline measurements of pulmonary function in the children with primary ciliary dyskinesia (PCD)

\begin{tabular}{|c|c|c|c|c|c|c|c|c|c|c|c|c|}
\hline & \multicolumn{12}{|c|}{ PCD subjects } \\
\hline & 1 & 2 & 3 & 4 & 5 & 6 & 7 & 8 & 9 & 10 & 11 & 12 \\
\hline$\overline{F E V} 1 \%$ & 74 & 85 & 72 & 63 & 92 & 75 & 85 & 85 & 48 & 68 & 61 & 65 \\
\hline FVC \% & 92 & 103 & 74 & 78 & 106 & 90 & 120 & 113 & 66 & 86 & 89 & 74 \\
\hline FEF $25-75 \% \%$ & 68 & 59 & 71 & 45 & 70 & 60 & 46 & 48 & 25 & 44 & 34 & 56 \\
\hline PEFR \% & 90 & 87 & 84 & 82 & 84 & 77 & 107 & 93 & 57 & 88 & 80 & 84 \\
\hline
\end{tabular}

Values are presented as percentage of predicted for age, height and sex [14, 15]. FEV1: forced expiratory volume in one second; FVC: forced vital capacity; FEF25-75\%: forced mid-expiratory flow; PEFR: peak expiratory flow rate. 
than their baseline value. Two children showed unequivocal bronchoconstriction to exercise (including one of the five who also bronchodilated) and one showed a borderline bronchoconstriction. One normal subject had a rise in PEFR of $>20 \%$ on exercise, and one had a fall in PEFR of $29 \%$ despite having no symptoms. Ten of twelve children with PCD had a better bronchodilator response to exercise than $\beta_{2}$-agonists, $\mathrm{p}<0.002$. Only three children with PCD bronchodilated with salbutamol (table 2). No fall in arterial oxygen saturation was demonstrated at any time during the study.

\section{Discussion}

The main new finding of this study is that children with PCD may exhibit bronchodilatation to exercise. Their response was greater to exercise than to $\beta_{2}$-agonists, and indeed one subject with PCD actually bronchoconstricted with salbutamol. This pattern of variable airflow obstruction is more akin to that which may be seen in cystic fibrosis rather than asthma $[8,9]$.

Pulmonary function in children with PCD is characterized by a mild to moderate obstructive pattern. Possible pathological changes accounting for this include, airway smooth muscle hypertrophy and fibrosis, intraluminal secretions and altered lung mechanics secondary to repeated infection. Clearance of airway secretions is likely to be facilitated by bronchodilatation, and the aim of this study was to determine whether $\beta_{2}$-agonists or exercise would better achieve this. In most cases, exercise was a more potent bronchodilator than $\beta_{2}$-agonists. Indeed, the latter may rarely cause bronchoconstriction. There were some individual variations in airway response but in this small group, it was not possible to predict airway responsiveness from baseline lung function. The duration of the bronchodilation response resulting from exercise was at least $30 \mathrm{~min}$ and chest physiotherapy would usually be carried out within this time.

Evidence-based practice encourages the use of exercise in the management of many respiratory diseases for a number of reasons including: enhanced clearance of bronchial secretions [16], improvements in pulmonary function and cardiorespiratory fitness [17], and a reduction in the sensation of breathlessness [18]. It would appear from the results of this study that exercise can and should be promoted in the management of PCD. A subsidiary aim of this study was to assess the safety of exercise in PCD. Although no patient desaturated in this study, it is possible, however, that more severely affected patients might require oxygen supplementation during exercise.

In conclusion, this paper describes airway obstruction in children with primary ciliary dyskinesia and reports for the first time the intrasubject variation that can be anticipated in spirometry in these children. We conclude that, in children with primary ciliary dyskinesia (PCD), exercise appears to be a more powerful bronchodilator stimulus than $\beta_{2}$-agonists. However, because there is unpredictable individual variation in response we recommend a physiological assessment before any treatment regimen based on exercise or $\beta_{2}$-agonist therapy is implemented.
Acknowledgements: The authors wish to thank the children, siblings and parents from the PCD Family Support Group for their enthusiastic participation and encouragement, and Allen Hanburys Ltd for covering their travel expenses.

\section{References}

1. Turner JAP, Corkey CWB, Lee JYC, Levison H, Sturgess J. Clinical impressions of immotile cilia syndrome. Paediatrics 1981; 67: 805-810.

2. Levison H, Mindorff CM, Chao J, Turner JAP, Sturgess JM, Stringer DA. Pathophysiology of the ciliary motility syndromes. Eur J Respir Dis 1983; 64 (Suppl. 127): 102116.

3. Corkey CWB, Levison H, Turner JAP. The immotile cilia syndrome. Am Rev Respir Dis 1981; 124: 544-549.

4. Greenstone MA, Rutman A, Dewer A, Mackay I, Cole PJ. Primary ciliary dyskinesia: cytology and clinical features. $Q$ J Med 1988; 67: 253: 405-430.

5. Nickerson BG, Lemen RJ, Gerdes CB, Wegmann MJ, Robertson G. Within-subject variability and percent change for significance of spirometry in normal subjects and in patients with cystic fibrosis. Am Rev Respir Dis 1980; 122: 855-859.

6. Sterk PJ, Fabbri LM, Quanjer PH, et al. Airway responsiveness. Eur Respir J 1593; 6: Suppl. 16, 53-83.

7. Jones RS, Buston MH, Wharton MJ. The effect of exercise on ventilatory function in the child with asthma. $\mathrm{Br} J$ Dis Chest 1962; 56: 78-86.

8. Skorecki K, Levison H, Crozier DN. Bronchial lability in cystic fibrosis. Acta Paed Scand 1976; 65: 39-44.

9. Macfarlene PI, Heaf D. Changes in airflow obstruction and oxygen saturation in response to exercise and bronchodilators in cystic fibrosis. Pediatr Pulmonol 1990; 8: 4-11.

10. Zach MS, Oberwaldner B, Forche G, Polgar G. Bronchodilators increase airway instability in cystic fibrosis. $A m$ Rev Respir Dis 1985; 131: 537-543.

11. Rutland J, Cole JP. Non invasive sampling of nasal cilia for measurement of beat frequency and study of ultrastructure. Lancet 1980; 2: 564-565.

12. Silverman M, Anderson SD. Standardisation of exercise tests in asthmatic children. Arch Dis Child 1972; 47: 882 889.

13. Jones ML, Campbell EJM, eds. Clinical Exercise Testing, 2nd edn. Philadelphia, W.B Saunders, 1980; pp. 34.

14. Cotes JE, ed. Lung Function: Assessment and Application in Medicine, 4th edn. Oxford, Blackwell Scientific Publications, 1993; pp. 460.

15. Polgar G, Promadhat U, eds. Pulmonary Function Testing in Children. Philadelphia, W.B. Saunders, 1971; pp. 186.

16. Bilton D, Dodd ME, Abbot JV, Webb AK. The benefits of exercise combined with physiotherapy in the treatment of adults with cystic fibrosis. Respir Med 1992; 86: $507-$ 511.

17. Strangheel JK, Winnem M, Roaldsen K, deWit S, Notgewich JH, Nilson BR. Young patients with cystic fibrosis; attitude toward physical activity and influence on physical fitness and spirometric values of a 2 -week training course. Int J Sports Med 1988; 9: 19-24.

18. O'Neill PA, Dodds M, Phillips B, Poole J, Webb AK. Regular exercise and reduction of breathlessness in patients with cystic fibrosis. Br J Dis Chest 1987; 81: 62-69. 